\title{
Gelombang Baru Studi Islam dan Masyarakat Muslim Pasca Orientalisme
}

\author{
Muhammad Rofiq \\ Fakultas ISIPOL, Universitas Gadjah Mada Yogyakarta. \\ Email:mrofiqmz@yahoo.com
}

\begin{abstract}
This article underlines some misunderstanding in the Muslim communities concerning three concepts: orientalism, evangelism and imperialism. In the writer's view point, orientalism has often been seen in it's a pejorative and simplified meaning. Therefore the writer attempts to describe Western scholars' responses to this understanding, and tries to explain some requirements that have been formulated by modern scholars, either Muslim or non-Muslim, regarding approaches in the study of Islam in the framework of religious studies. The writer also argues to what extent that contemporary Islamic studies (dirâsah islâmiyyah mu'âshirah) is supposed to synthesized between classical Islamic studies and western intellectual history in the study of Islam in the modern world.
\end{abstract}

Keywords: Orientalism, Edward Said, studi Islam kontemporer, inclusivism.

\section{ABSTRAK}

Tulisan ini menggarisbawahi beberapa kesalahpahaman internal umat Islam mengenai tiga entitas, yaitu: orientalism, evangelism dan imperialism. Dalam pembacaan penulis, orientalisme dalam

kacamata kebanyakan umat Islam selalu dipandang secara peyoratif dan direduksi secara simplifikatif. Dalam artikel ini penulis kemudian mendeskripsikan beberapa respon balik dari sarjana-sarjana Barat atas kesalahpahaman tersebut. Selain itu, penulis mendeskripsikan pula beberapa prasyarat yang telah berhasil dirumuskan oleh sejumlah sarjana modern (muslim maupun non-muslim) mengenai pendekatan (approach) dalam mengkaji agama Islam dalam kerangka disiplin ilmu studi agama-agama (religious studies). Pada akhirnya, penulis kemudian menyajikan pembahasan bagaimana dirâsah islâmiyyah mu'âshirah semestinya menampilkan diri dengan melakukan sintesa antara islamic studies di era klasik dan pengalaman intelektual Barat dalam melakukan studi terhadap dunia Islam di era modern.

Kata Kunci: Orientalisme, Edward Said, studi Islam kontemporer, inklusivisme.

\section{PENDAHULUAN}

Sampai saat ini pro-kontra tentang wacana akademik seputar orientalisme ${ }^{1}$ di tengah umat Islam masih saja terus berlanjut. Tidaklah terlalu simplistis jika dikatakan bahwa kecenderungan umum yang beredar di kalangan umat Islam adalah pandangan yang serba negatif terhadap orientalisme. ${ }^{2}$ Pengalaman terjajah di masa lalu ${ }^{3}$ dan pandangan relativisme kebudayaan bisa jadi merupakan katalisator paling bertanggungjawab terhadap munculnya pandangan negatif terhadap orientalisme sebagai mainstream di kalangan umat Islam. Sikap seperti itu mendapatkan justifikasinya manakala 
beberapa intelektual muslim menemukan sejumlah tesa orientalis yang berseberangan seratus delapan puluh derajat dengan apa yang selama ini telah menjadi kebenaran yang mapan (kredo) dalam pemikiran umat Islam. ${ }^{4}$ Tesa-tesa tersebut kemudian dituduh sebagai bagian dari makar dengan menggunakan metode ilmiah dan sistematis untuk menghancurkan Islam. ${ }^{5}$ Maka tak pelak lagi, tiga fakta di atas telah melahirkan pandangan yang mencampuradukkan antara orientalism sebagai bagian dari wilayah intelektualisme murni dengan colonialism dan evangelism. ${ }^{6}$ Pertanyaan yang muncul adalah benarkah ketiga hal itu sejak awal adalah entitas yang saling terkait satu sama lain dan tidak bisa dipisahkan?

Tulisan ini akan menguraikan bagaimana semestinya perspektif proporsional yang harusnya dibangun oleh umat Islam di era modern ini terhadap orientalisme dan bagaimana pula umat Islam dapat mereformasi paradigma mereka mengenai dunia Barat dan sekaligus wajah dari islamic studies itu sendiri.

\section{PROBLEM ONTOLOGIS ORIENTALISME}

Tampaknya harus segera ditegaskan di awal bahwa pandangan yang mencampuradukkan antara ketiga entitas itu adalah pandangan yang tidak tepat. Perspektif filsafat ilmu kurang lebih bisa memberikan jawaban terhadap percampuradukkan di atas. Sesungguhnya bisa dipastikan bahwa kesalahpahaman terhadap esensi orientalisme terjadi karena para intelektual (muslim maupun non-muslim) telah terlebih dahulu terjebak pada perspektif aksiologis dari orientalisme, ${ }^{7}$ sebelum terlebih dahulu melakukan proses penjernihan masalah dalam tataran ontologis. Padahal, sisi ontologis dari segala sesuatu sudah semestinya tidak hilang ditelan oleh stereotyping yang dilakukan secara simplifikatif terhadap permasalahan apapun, termasuk terhadap orientalisme. Secara ontologi ${ }^{8}$, sesungguhnya orientalisme tak lain adalah sebuah disiplin ilmu yang muncul sebagai sebuah keniscayaan dari perjumpaan antar komunitas yang berlainan (encounter of different nation). Perjumpaan itu kemudian membangkitkan rasa ingin tahu (curiosity) yang tinggi dan pada akhirnya memunculkan penelitian (inquiry) sebagai upaya untuk mengetahui sisi lain dari komunitas yang asing ada di sampingnya. Jika dipahami dengan perspektif seperti ini maka keterburu-buruan yang mencampuradukkan antara evangelism, colonialism dan orientalism akan segera bisa disudahi.

Jika dirunut genealoginya, paradigma negatif terhadap orientalisme ini menemukan momentumnya untuk tumbuh subur di kalangan umat Islam saat seorang outsider (meminjam bahasa Fazlur Rahman) ${ }^{9}$ dan tokoh Kristen dari Palestina; Edward Said, menerbitkan bukunya yang berjudul Orientalism. Erward dalam bukunya tersebut melakukan ideologisasi dan politisasi terhadap orientalisme, sehingga orientalisme pasca Edward Said berubah menjadi lebih peyoratif. Edward Said menyatakan bahwa orientalisme adalah usaha manipulasi kolonial terhadap dunia Timur. ${ }^{10}$

Paradigma Edward ini jika dianalisis komponen pembentuknya maka kita bisa melihat pengaruh Michael Foucoult yang kental pada diri Edward. Foucoult mereduksi makna ilmu dan pengetahuan dan mengidentikannya dengan kekuasaan. Padahal awalnya keduanya dianggap sesuatu yang netral, baik dan bermanfaat. ${ }^{11}$ Foucoult percaya bahwa karena terlibat dalam dunia 
nyata, ilmu pengetahuan terlibat pula dalam perjuangan kekuasaan dan ketegangan yang membentuk dunia. ${ }^{12}$ Dalam menerapkan teori Foucolt ini, jelas Edward Said tampak banyak sekali melakukan tindakan gebyah uyah (menggeneralisir) sehingga berimplikasi pada, seperti yang dinyatakan oleh Richard Martin, penyulitan sejumlah pengkaji Timur Tengah dan Islam dalam banyak kesempatan. ${ }^{13}$

Edward Said melakukan kesalahan dengan mengindentikan subyek orientalisme sebagai bangsa yang memiliki agenda kolonialisme. Richard King ketika mengkritik Edward tentang generalisasi ini menyatakan bahwa analisa Edward tentang orientalisme Perancis, Inggris dan sampai batas tertentu Amerika tidak menyentuh tradisi kesarjanaan orientalis yang kuat di Jerman, di mana Jerman tidak memiliki kerajaan kolonial di Timur. Generalisasi Edward Said yang terlalu berlebih juga bisa kita temukan ketika ia mengidentikkan obyek orientalisme sebagai obyek penjajahan. Ia mengabaikan fakta bahwa Jepang yang diminati para orientalis adalah bangsa yang belum pernah sama sekali dijajah oleh Barat. Selain itu, Edward juga mengindentikan orientalisme sebagai senjata untuk mematikan obyek yang dikaji dan tidak memperhitungkan cara bagaimana masyarakat Timur menggunakan, memanipulasi dan mengkonstruksi responrespon positifnya sendiri untuk menentang koloanialisme dengan konsepsi-konsepsi orientalis. $^{14}$

Untuk mengkritik Edward Said, Richard King dalam karyanya Orientalism and Religion Postcolonial theory, India and The mystic East mencatumkan hasil penelitiannya tentang orientalisme di India. Sembari mengutip David Kopf ia menulis ${ }^{15}$ :
Kopf, in fact, believes that Said has provided an overly negative and one-sided analysis, which fails to take into account the positive elements within Orientalist discourses. He suggests that modern Orientalism was Born in Calcutta in 1784 with the establishment of the Asiatic Society of Bengal. British Orientalisme can be said to have given birth to the Bengal Renaissance since it 'helped Indians to find an indigenous identity in the modern world. Kopf suggest that these Orientalist 'were men of social action, working to modernize Hindu culture from within'.

(Pada kenyataannya, Kopf percaya bahwa Said telah membuat analisis yang sangat negatif dan timpang, yang gagal melihat unsur-unsur positif dalam wacana orientalis. Dia mengatakan bahwa orientalisme lahir di Kalkuta pada tahun 1784 dengan berdirinya Masyarakat Asiatik Bengal. "Orientalisme Inggris bisa dikatakan telah mendorong lahirnya Renaisans Bengal karena orientalisme Inggris membantu bangsa India menemukan identitas indigenous-nya sendiri di dunia modern. Kopf berpendapat bahwa orientalis-orientalis ini adalah orang-orang gerakan sosial yang bekerja untuk memodernisasi kebudayaan Hindu dari dalam).

Konsep agama Hindu, menurut Richard King, pada awalnya justru digulirkan oleh orientalis-orientalis barat berdasarkan pengamatan mereka terhadap pemahamanpemahaman Judeo-Kristen atas istilah “agama”. Konsepsi agama Hindu tersebut diakibatkan oleh interaksi antara orientalis Barat dan pundit Brahmanikal. Konstruk ini kemudian diadopsi dan diadaptasi oleh kaum nasionalis Hindu untuk memperoleh 
swatantra (swaraj) dan merespon hegemoni imperial Inggris. ${ }^{16}$ Fakta temuan Richard King menunjukkan bahwa sikap simplifikasi radikal ala Edward Said tidaklah bersandarkan pada argumentasi yang bisa dibenarkan karena menggunakan logika deduktif. Richard Martin menyebut bahwa karya tersebut justru membuat chauvinisme rasial dan politik. ${ }^{17}$

Genealogi pandangan Edward Said yang mengidentikkan kolonialisasi dan apropriasi terhadap orientalisme bisa ditemukan pada teori hermeneutika. Sebagaimana dinyatakan Gadamer dalam Truth and Method yang dikutip Richard King bahwa memahami sesuatu, secara implisit melibatkan prasangka keterkondisian seseorang; orang tidak dapat mengelak kepemilikian agenda atau perspektif tentang sesuatu atas dasar kekhususan kultural dan historisnya. Tentang hal ini, Richard King menulis:

In contrast to this, Gadamer's work is clearly an attempt to reassess the importance of both tradition and prejudice in the act of understanding. Gadamer argues that both tradition and prejudice are inevitable features of any act of interpretation since they reflect the historical and cultural situatedness of human beings.

Thus, understanding is conditioned by the past (our 'tradition') as well as by our own present circumstances and agendas (our prejudice).

The particularity of our situation makes any notion of an objective and value-free interpretation inherently problematic. ${ }^{18}$

(Berkebalikan dengan ini, karya Gadamer adalah jelas-jelas sebuah upaya untuk menegaskan kembali pentingnya tradisi dan prasangka dalam memahami sesuatu.

Gadamer berpendapat bahwa keduanya, tradisi dan prasangka, merupakan ciri-ciri yang pasti hadir dalam tindakan menafsir, karena keduanya merefleksikan

keterkondisian historis dan kultural umat manusia. Maka, memahami (understanding) terkondisikan oleh masa lalu (tradisi kita) dan juga oleh sekeliling dan agenda (prasangka) kita sendiri pada saat sekarang. Kekhususan situasi ini membuat konsep penafsiran yang obyektif dan bebas nilai menjadi problematis secara inheren).

\section{BAGAIMANA SEHARUSNYA ORIENTALISME}

Jika secara ontologis, orientalisme harus bersih dari stereotype, dan secara hermeneutis dimungkinkan adanya perbedaan pandangan orientalis dengan pandangan muslim (karena perbedaan keterkondisian historis dan kultural), namun dalam tataran praktikal kita tidak bisa menerima tanpa reserve semua pemikiran orientalis dan mengenerasilir bahwa mereka memiliki kesamaan titik tolak. ${ }^{19}$ Fazlur Rahman seorang yang sangat bersahabat dan sekaligus kritis dengan tradisi orientalisme di Barat misalnya, pernah secara keras mengkritik John Wansbrough yang menulis buku Quranic Studies. Dalam karyanya itu, seperti dikutip oleh Rahman, Wansbrough mencoba membuktikan tesatesanya (1) bahwa al-Quran adalah sebuah kitab ala tradition juvie karena tercipta di dalam suasana yang penuh denan perdebatan sektarian Yahudi-Kristen, (2) bahwa al-Quran adalah perpaduan dari berbagai tradisi, (3) alQuran adalah seuah ciptaan setelah kehadiran Muhammad. Sejalan dengan kritik Rahman terhadap Wansbrough dalam quranic studies, ia juga mengkritik John Burton yang menyatakan bahwa keseluruhan teks al-Quran diedit, dicek, dan disebarkan oleh nabi Muhammad sendiri. Tentang 
temuan-temuan tokoh-tokoh ini Rahman menilai bahwa karya-karya mereka menunjukkan sebuah pandangan eksternal yang mengendalikan mereka. ${ }^{20}$

Atas dasar itulah Rahman kemudian mengusulkan disepakatinya prasyaratprasyarat untuk dilakukannya studi terhadap agama lain. Studi agama, menurutnya, harus dilakukan di atas pemahaman intelektual yang ilmiah, yaitu yang tidak didirikan atas permusuhan (inimical) atau prasangka (prejudice) terhadap objek kajiannya dan semestinya terbuka (open minded) dan jika mungkin simpati (sympathetically). ${ }^{21}$ Tentang prasangka tersebut ia menjelaskan bahwa dalam konteks akademis prasangka tidak hanya datang dalam bentuk emosi keagamaan, namun juga bisa muncul ketika melakukan kategori-kategori prakonsepsi. Rahman pun mengakui bahwa kajian akademis para orientalis bisa saja terjebak pada reduksionisme, yaitu manakala mereka berusaha menjelaskan kelahiran Islam dengan merujuk pada pengaruh-pengaruh Yahudi, Kristen dan lainnya.

Charles J Adams, tokoh yang menggeluti sejarah agama-agama dan studi Islam di Universitas Chicago, membuat klasifikasi metode para orientalis dalam mengkaji Islam. Ia menyatakan bahwa minimal ada dua pendekatan yang biasa digunakan ketika mengkaji Islam sebagai agama dan kebudayaan, yaitu pendekatan normatif (mi'yâriy) dan deskriptif (washfiy). Pendekatan normatif adalah cara pandang terhadap agama dari orang yang mempunyai dan meyakini kebenaran-kebenaran transedental dari agama itu sendiri. Dari segi normatif, Adam mengelompokkanya menjadi tiga, yaitu: a) misionarisme (tabsyîri), b) apologisme (i'tidzâriy) dan c) pendekatan irenis (simpatik).
Ketiga motivasi dalam pendekatan pertama ini masih mencerminkan sikap yang tidak sesuai dalam melakukan studi terhadap agama orang lain karena masih mengajak orang lain agar juga mengakui apa yang menjadi keyakinan penganut agama tersebut. ${ }^{22}$

Para pemikir Barat kemudian menyadari bahwa pendekatan normatif dalam studi agama memiliki banyak kelemahan dan hanya akan menghasilkan pertentangan abadi antar umat beragama, sebab tujuan pokok dari pendekatan ini adalah melakukan penguasaan (Arab: saitharah) dan misionarisme terhadap umat agama lain. ${ }^{23}$ Maka, pendekatan deskriptif yang telah digunakan sebagian orientalis bisa dijadikan pendekatan alternatif dari pendekatan normatif. Pendekatan ini muncul sebagai jawaban terhadap motivasi keingintahuan intelektual atau akademis (intellectual curiositiy, isybâ' al-raghbah alinsâniyyah). Menurut Martin, aspek deskriptif studi agama bergantung kepada disiplin-disiplin ilmu lain, yaitu; a) filologi-historis. Metode ini digunakan untuk mengkaji warisan tekstual atau dokumen-dokumen masa lampau dari khazanah keislaman. b) ilmu-ilmu sosial. Penelitian dalam ilmu sosial bertujuan untuk menemukan aspek empiris dari keberagaman. Dengan menggunakan pendekatan ilmu-ilmu sosial, agama akan dijelaskan dengan beberapa teori, misalnya agama merupakan perluasan dari nilai-nilai sosial. c) fenomenologi. ${ }^{24}$ Dalam pendekatan ini ada beberapa premis yang dijadikan pijakan, yaitu pertama, fenomena keagamaan harus dilihat dan diteliti dengan cara yang terbuka, akutanbel dan dengan empati. Kedua, fenomologi harus bersumpah meninggalkan semua bentuk penjelasan yang 
sifatnya reduksionis mengenai agama. Ketiga, fenomenologi agama adalah apa yang dialami oleh pemeluk agama, apa yang dirasakan, dikatakan dan dikerjakan, serta bagaimana pula pengalaman tersebut bermakna baginya. $^{25}$

Sejalan dengan taksonomi pendekatan terhadap studi agama yang dilakukan Charles Adam tersebut, kita bisa menemukan bahwa kesadaran untuk melakukan studi agama di kalangan ilmuwan Barat terus meningkat ke arah kesadaran untuk menemukan obyektifitas dan sikap simpati kepada agama lain. Jadi tesis Gadamer bahwa seseorang seorang peneliti tidak akan bisa menanggalkan keterkondisian historis dan kulturalnya sesungguhnya bisa didamaikan dengan teori Adam bahwa semestinya prasangka harus ditekan sekuat mungkin. Bahkan tidak hanya itu, seorang orientalis (lagi-lagi terpaksa harus menggunakan istilah ini) harus melakukan semacam tindakan meninggalkan diri sendiri (epoche) dan berusaha menghidupkan pengalaman orang lain.

Implikasi yang tak terhindarkan dari adanya sikap empati dalam memandang agama lain pada yang saat sama bisa menjadi alternatif bagi paradigma binarian yang serba memandang agama lain dengan penuh curiga dan sebagai musuh. Dunia sudah tidak bisa lagi dikendalikan dengan cara berfikir dikotomistik, penuh nuansa clash dan rivalitas. Dunia milik bersama ini harus dikelola secara damai, santun penuh pengertian antar berbagai macam kultur dan pemeluk bermacam-macam agama yang mendiaminya.

\section{MASA DEPAN ISLAMIC STUDIES}

Pada tahun 1999, Hasan Hanafi, seorang intelektual berkebangsaan Mesir menerbitkan bukunya yang berjudul alMuqaddimah fi 'Ilmi al-Istighrâb (Pengantar Menuju Oksidentalisme). Buku ini termasuk karya awal yang ditulis oleh cendikiawan muslim tentang bagaimana peradaban Islam dan dunia Timur umumnya menyusun kerangka berfikir dalam menghadapi orientalisme yang dalam pandangan Hanafi sarat dengan kelemahan. Kelemahan orientalisme itu di antaranya adalah saratnya muatan eurosentris, di mana setiap kajian didirikan di atas sikap superioritas Barat terhadap dunia Timur. Oleh karena itu, menurut Hanafi, tugas berat oksidentalisme adalah melakukan usaha untuk mensejajarkan antara Barat dan dunia Islam, di mana Islam tidak lagi diposisikan sebagai objek dan barat sebagai subyek, namun berganti posisi Islam sebagai subjek dan barat sebagai objek.

Sebagai sebuah karya yang mewakili kepedulian dan komitmen mengangkat peradaban Islam menjadi peradaban terkemuka, karya ini patut diacungi jempol. Namun, jika ditelisik lebih dalam sesungguhnya karya ini menunjukkan beberapa kesalahan cara pandang pula, yaitu adanya sikap defensif, apologis dan reaksioner terhadap dunia Barat. Dalam hal ini sesungguhnya Hasan Hanafi mengulang kesalahan yang dilakukan oleh Samuel Huntington dengan tesa Clash of Civilizationnya yang membagi dunia hanya kepada dua kutub. Cara pandang yang binarian (membagi dunia dalam binary opposition/ wajhan bi wajhin) seperti ini justru menunjukkan adanya sikap yang tidak toleran, inklusif dan kental dengan nuansa rivalitasnya. Kondisi dunia saat ini tidak bisa lagi diatur dan dikendalikan oleh sikap bermusuhan yang tidak berkesudahan antar 
umat manusia.

Pertanyaan yang muncul selanjutnya, lantas seperti apa format hubungan dunia Barat dan Islam dalam bidang intelektual harus kita bangun? Dengan kata lain, jika Barat tidak diposisikan sebagai obyek kajian, akan seperti apa ia kita perlakukan? Apakah sebagai musuh ataukah justru sebagai partner? Untuk menjawab kerumitan ini, beberapa intelektual mencoba memunculkan istilah dirâsah islâmiyah mu'âshirah (contemporary islamic studies, studi Islam kontemporer) sebagai studi yang muncul pasca era kolonialisme dan bahkan orientalisme. Studi ini lahir sebagai sintesa antara Islamic studies di era klasik dan pengalaman intelektual barat dalam melakukan studi terhadap dunia Islam di era modern. Kedua-duanya memiliki kekurangan dan kelebihan sehingga masingmasing harus disatukan.

Harus diakui bahwa produk yang lahir dari islamic studies di era klasik dengan beberapa pengecualian dari karya sebagian ulama, mengandung banyak anomali. Diantaranya adalah, dengan meminjam istilah Amin Abdullah, terlalu kental nuanasa believe (teologis) nya dan sangat normatif (deduktif) sehingga cenderung mengabaikan kajiankajian yang lebih bersifat historis dan empirik. Kelemahan ini disebabkan antara lain oleh tidak adanya induksi dan investigasi sistemik dan empirik mengenai manusia dan realitas sosial masyarakat. ${ }^{26}$ Apa yang lahir dari rahim peradaban Islam, terutama di era stagnasi cenderung hanya bersifat repetitif (alqirâah al-mutakarrirah), minim kreasi dan menghindar dari apa yang disebut Thomas Kuhn sebagai scientific revolution. ${ }^{27}$ Bangunan pemikiran yang lahir dari peradaban Islam di era klasik tidak dipahami sebagai formula yang lahir dalam lanskap tertentu dan tidak tidak terlepas dari ruang dan waktu, sehingga beberapa pemikir mengidentifikasi bahwa telah terjadi apa yang disebut dengan sakralisasi pemikiran keagamaan (taqdîs alafkâr al-dîniyyah) dalam realitas pemikiran keislaman saat ini. Ada semacam keengganan untuk melakukan pembacaan kritis (naqdî) dan ijtihad ulang terhadap ilmu kalam, fikih, tasawuf, tafsir, dan ilmu-ilmu lainnya sebagai hasil karya yang lahir dari produk era klasikskolastik. Sehingga produk-produk tersebut diterima secara for granted dan minim penalaran terhadap konteks sosio-kulturalpolitis di mana pendapat tersebut dilahirkan.

Sementara kajian di dunia Barat telah mengalami revolusi yang sangat cepat, di mana dunia keilmuan telah mengalami titik kulminasi. Apa yang sebelumnya hilang dari peradaban Islam, diantaranya yaitu curiosity terhadap pengetahuan empirik, mampu ditemukan dan dipoles sehingga lebih menemukan vitalitas untuk berkembang dan memberikan kontribusi bagi kehidupan manusia. ${ }^{28}$ Adanya discoveries dalam lingkup ilmu humaniora dan ilmu alam adalah fenomena ril yang kita temukan paska bangkitnya peradaban Barat. Jika di dunia Islam kajian historis-sosiologis seperti yang digagas oleh Ibnu Khaldun misalnya ditelantarkan dan dikalahkan oleh disiplin yang bersifat teologis-deduktif, di Barat kajian yang bercorak seperti itu diterima dengan tangan terbuka dan berhasil dikembangkan dengan baik. Agama yang pada kajian keislaman era klasik lebih banyak didekati dan dikaji hanya sebagai way of life sehingga selalu saja kesan sakral tak bisa dilepaskan, di Barat juga ditempatkan secara lebih manusiawi sehingga ia bisa diteliti dan dikritisi sebagai realitas kemanusiaan yang profan. $^{29}$ 
Islamic studies di era pasca orientalisme ini bisa diposisikan sebagai jawaban dan alternatif terhadap mampetnya pemikiran keislaman yang sudah sejak lama telah dirasakan oleh sebagian intelektual muslim. ${ }^{30}$ Problem yang dihadapi oleh umat Islam dan dunia kemanusiaan menuntut agar islamic studies di era modern lebih kontributif. Maka, sintesa dari dua gelombang itu dalam kerangka islamic studies adalah sebuah keniscayaan. Kedua gelombang itu harus diposisikan sebagai dua instrumen yang saling bekerja sama, melengkapi dan juga saling mengkritisi kekurangan masing-masing. Pola kerjasama antar dua gelombang ini oleh Amin Abdullah disebut sebagai paradigma interkoneksi, yaitu sebuah paradigma yang menghubungkan secara sirkuler pendekatanpendekatan yang lahir dari ilmu-ilmu sains, sosial dan keislaman. ${ }^{31}$ Pendekatan ini akan mengakhiri dikotomi wajah pendidikan yang bercorak dogmatis dan yang bercorak murni scholarly work. Dengan kata lain, meminjam istilah Richard Martin, paradigma ini akan mengakhiri dualisme pendidikan antara Universitas Leiden dan al-Azhar serta menyatukan kutub believer dan historian. ${ }^{32}$

Islamic studies kontemporer yang mendapatkan celupan dari dua gelombang besar tersebut kemudian akan muncul dengan wajah yang inklusif (terbuka) dengan masukan baru dan tidak terpaku dengan warisan masa lalu. Sesungguhnya ada beberapa tokoh yang bisa kita sebutkan sebagai representasi dari islamic studies kontemporer tersebut, diantaranya adalah Muhamamd Arkoun dari Aljazair, Nasr Hamid Abu Zaid dari Mesir, Fazlur Rahman dari Pakistan, Abid al-Jabiri dari Maroko, Abdullah Ahmad an-Naim dari Sudan tokohtokoh lainnya. Harus diakui bahwa sebagian besar dari mereka ini hanyalah sekelompok muslim minoritas yang lahir dari tradisi ilmiah Barat. Mereka dibesarkan dalam iklim intelektual yang kritis dan sekaligus terbuka terhadap warisan peradaban Barat. Namun sungguh satu hal yang sangat ironi ketika mereka sedang berupaya mencarikan sebuah formula agar agama Islam tetap relevan dengan modernitas, mereka malah dituduh nyeleneh, antek asing, bahkan sampai dikafirkan. Sikap tidak kritis, eksklusif dan lebih-lebih penuh curiga merupakan bahaya besar yang menghadang kemajuan pemikiran dan peradaban Islam di era kontemporer ini.

\section{KESIMPULAN}

Dari pemaparan di atas, dapat digarisbawahi bahwa orientalisme adalah sesuatu yang pada awalnya merupakan entitas yang terpisah dengan evangelism dan colonialism. Sehingga mencampuradukkan ketiganya menurut penulis jelas adalah tindakan simplikasi yang tidak dapat diterima. Namun diakui pula bahwa dalam perjalanannya orientalisme pernah 'ditunggangi' oleh sejumlah kepentingan yang bersifat nonakademik sehingga tidak heran jika tesa yang dimunculkan cenderung reduktif dan apologetik.

Respon sebagian sarjana Islam dengan memunculkan disiplin 'Studi Barat (oksidentalisme, 'ilmu al-istighrâb)' menurut penulis hanya akan melanjutkan dikotomi dan pandangan binarian antara Barat dan Timur, sehingga pada akhirnya berpotensi melahirkan konflik antar peradaban (clash of civilization) di era modern. Untuk itu, tulisan ini menawarkan satu formula agar umat Islam melakukan reformasi sifat dasar (nature) studi Islam, yakni agar tidak 'melulu' teologis, deduktif, ahistoris dan pada akhirnya 
menjadi sesuatu yang sakral (muqaddas).

Namun studi Islam bisa pula bersifat empirik, induktif, historis dan bahkan profan sekalipun. Untuk sampai ke arah sana, langkah yang dapat dimulai adalah dengan memandang secara kritis dan proporsial terhadap warisan (turâst) Islam di masa lalu dan melakukan apresiasi terhadap intelektualisme dan empirisme di dunia Barat. Wallahu A'lam.

\section{CATATAN AKHIR}

$1 \quad$ Untuk kepentingan membuat runtutan historis yang akan menggiring munculnya gelombang baru dalam studi Islam, penulis di sini mengabaikan seruan Richard Martin untuk mengganti terminologi orientalisme yang garang dan sangat idelogis dengan terminologi islamic studies atau middle eastern studies yang lebih bersahabat. Baca Richard Martin, Approaches to Islam in Religious Studies (University of Arizona Press, 1985), h. 10-6.

2 Seorang penulis bahkan mengasosiasikan orientalisme dengan diabolisme intelektual.

3 Muhammad al-Bahi, seorang penulis di Mesir menerbitkan buku tentang hubungan orientalisme dengan penjajahan yang berjudul al-Fikru al-Islâmiy alHadîst wa Shilâtuhu bi al-Isti'mâr al-Gharbiy (Pemikiran Islam Kontemporer dan Hubungannya dengan Penjajahan Barat), (Cairo: Maktabah Wahbah, 1997).

4 Pandangan negatif tentang orientalisme misalnya bisa kita temukan pada kesimpulan yang dibuat oleh Ahmad Samaloyevic dalam disertasinya untuk Fakultas Darul Ulum di Universitas Kairo. Setelah memaparkan berbagai definisi dari beberapa intelektual arab mengenai orientalisme (al-istisyrâq), ia menyimpulkan bahwa orientalisme adalah alat intelektual untuk menghancurkan Islam. Ahmad Samaloyevic, Falsafatu al-Istisyrâa wa Atsâruha fi al-Adabi al-'Arabi al-Mu'âshir (Cairo: Darul Fikri al-Arabi, 1998), h. 31.

5 Ditambah lagi adanya fakta sejumlah orientalis yang berlatar belakang sebagai gerejawan, alias seorang pendeta, seperti di era modern ada figur Montgomery Watt (w. 2006).

6 Pandangan ini seperti biasanya didukung oleh cara berfirkir deduktif murni yang bersandarkan argumentasi pada teks-teks keagamaan, misalnya biasa dikutip surat al-Baqarah ayat 120 dan al-Maidah ayat 85 . Menurut penulis, penafsiran ayat-ayat tersebut harus dilakukan secara kontekstual, yaitu diiringi dengan data-data empirik yang meyakinkan dan menggunakan logika berfikir yang lebih induktif.
7 Seorang penulis Arab, Abdur Rahman Hasan al-Maidani, misalnya meletakkan orientalisme sejajar dengan altabsyîr (misionarisme) dan al-isti'mâr (imperialisme), sebagai tiga sayap (ajnihah) konsprirasi musuh Islam untuk menghabisi agama Islam. la mendefinisikan terma al-mustayriqûn sebagai hum al-ladzina yaqûmûna bi al-dirâsah al-syarqiyyah min ghairi alsyarqiyyin wa yuqaddimûna dirâsâtihim wa nashâihahum wa washâyahum li: (a) al-mubasyyrîn bighâyyati tahqiq ahdâf al-tabsyîr, (b) al-musta'mirûn bighyyati tahqiq ahdâf al-isti'mâr. (Orang-orang yang melakukan studi tentang dunia timur melalui perspektif mereka sendiri dan mempersembahkan hasil studi mereka kepada; (a) para misionaris, (b) kolonialis). Abdur Rahman Hasan al-Maidani, Ajnihatu al-Makri alTsalâtsah, wa Khawâfiha, al-Tabsyîr, al-lstisyrâq, alIsti'mâr, Dirâsah wa Tahlîl wa Taujîh (Damaskus: Darul Oalam, 2000), h. 122.

8 Ontologi bisa didefinisikan sebagai penjelasan tentang keberadaan atau eksistensi yang mempermasalahkan akar yang paling mendasar tentang apa yang disebut ilmu pengetahuan. Soteriono dan Rita Hanafie, Filsafat Ilmu dan Metodologi Penelitian (Yogyakarta: Penerbit Andi, 2007), h. 61.

9 Fazlur Rahman, Approaches to Islam in Religious Studies (Tempe: The University of Arizona Press, 1985), 191.

10 Edward Said, Orientalisme, Menggugat Hegemoni Barat dan Mendudukkan Timur sebagai Subjek, (Yogyakarta: Pustaka Pelajar, 2010), h. 18.

11 Amin Abdullah, 2007. al-Maujah al-Islâmiyah al-Ukhrâ al-Istisyrâq wa al-Dirâsah al-Islâmiyah al-Mu'âshirah, dalam jurnal al-Jami'ah, Vol. 45. No. 2, h. 416

12 Tholchatul Choir, Ahmad Fanani (Ed.), Islam dalam Berbagai Pembacaan Kontemporer, (Yogyakarta: Pustaka Pelajar, 2007), h. 117

13 Richard Martin, Approaches.., h. 14

14 Richard King, Orientalism and Religion, Postcolonial theory, India and 'the mystic East', Routledge, 1999, h. 85

15 Richard King, Orientalism and Religion, h. 86-87

16 Richard King, Orientalism and Religion, h. 90

17 Richard Martin, Approaches... h. 15

18 Richard Martin, Approaches...., h. 73

19 Seperti dikatakan Gadamer sendiri bahwa: "rejecting the ideal of neutral and ahistorical objectivity does not necessarily lead to an anarchistic acceptance of any and all interpretation, however idriosyncratic, as equally valid. (menolak ideal objektifitas yang netral dan ahistoris tidak mengarah pada penerimaan sembarang dan semua penafsiran secara anarkistik betapapun ideokonstruksinya sebagai sama-sama sah). Richard Martin, Approaches..., h. 79

20 Fazlur Rahman, Mayor Themes of the Quran, diterjemahkan ke dalambahasa Indonesia oleh Anas Mahyuddin menjadi Ter a-tema Pokok al-Quran 
(Yogyakarta: Penerbit Pustaka, 1996), h. xv.

21 Fazlur Rahman, Approaches to Islam in Religious Studies dalam Approaches to Islam in Religious Studies (ed.), 1985, h. 192

22 Amin Abdullah, al-Maujah...h. 424-428

23 Amin Abdullah, al-Maujah, h., 428

24 Fazlur Rahman memberikan syarat untuk penggunaan fenomenologi ini, yaitu harus berdasarkan pengakuan terhadap al-Quran dan sunnah. Fazlur Rahman, Approaches... h. 197

25 Tholhatul Choir, Islam.. h. 284

26 Syamsul Anwar, Ke Arah Epistemologi Integratif, Mencari Arah Pengembangan Keilmuan dalam Rangka Pemekaran IAIN, (Yogyakarta: Pilar Media, 2004), h. 54.

27 Amin Abdullah, Islamic..., h. 50.

28 Pada dasarnya kelahiran peradaban Barat juga tidak lepas dari sumbangsih peradaban Islam. Muhammad lqbal pernah mengatakan bahwa Francis Bacon bapak empirisme barat adalah tokoh yang terpengaruh dari Ibnu Taimiyah. Muhammad Iqbal, The Reconstruction of Religion Thought in Islam diarabkan oleh Abbas Mahmud menjadi Tajdîdu al-Tafkîr al-Dîniy fi al-Islâm, (Alexandria: Dar al-Hidayah, 2006), h. 154.

29 Sebelumnya terlebih dahulu harus dicatat bahw apengertian agama di sini tidak hanya pada masalah doktrin dan ajaran semata, tetapi juga mencakup sejarah, tradisi, ritual dan budaya. Koentjaraningrat, seorang antropolog yang dibesarkan dalam tradisi ilmiah di Barat, misalnya menyatakan bahwa gejala religi itu merupakan gejala yang begitu kompleks sehingga tidak dapat diterangkan dengan satu hipotesa atau teori saja. la lalu mengusulkan agar konsep religi dipecah menjadi lima bagian yang bisa diteliti sendiri-sendiri namun memiliki keterkaitan satu sama lain. Kelima bagian itu adalah: (a) emosi keagamaan; (2) syitem keyakinan; (3) sistem ritus dan upacara; (4) peralatan ritus dan upacara; (5) umat beragama. Koenjtaraningrat, Sejarah Teori Antropologi I, (Jakarta: UI Press, 2007), h. 84.

30 Fazlur Rahman misalnya mengkritik tradisi syarh dan ta'lîa dalam fikih Islan yang dianggapnya tidak kritis, menjauh dari ijtihad dan hanya usaha untuk memapankan warisan fikih sebelumnya. Lih. Islam and Modernity: Transformation of an Intellectual Tradition (Chicago: The University of Chicago Press, 1982), h. 378

31 M. Amin Abdullah, Islamic Studies di Perguruan Tinggi (Yogyakarta: Pustaka Pelajar, 2009), h. 65

32 Richard Martin, Approaches...h. 15

\section{DAFTAR PUSTAKA}

Abdullah, M. Amin. 2009. al-Maujah al-Islâmiyah al-Ukhrâ, al-Istisyrâq wa al-Dirâsah al-Islâmiyyah al-Mu'âshirah, dalam jurnal al-Jami'ah, Vol. 45. No. 2. 2009. Islamic Studies di Perguruan
Tinggi. Yogyakarta: Pustaka Pelajar.

Ahmad Samaloyevic. 1998. Falsafah al-Istisyrâq wa Âstaruhâ fil Adabi al-Mu'âshir. Kairo: Darul Fikri alArabi.

Albahi, Muhammad. 1997. al-Fikru'l Islâmiy al-Hadist wa Silatuhu bi'l Isti'mâr al-Gharbiy. Kairo: Maktabah Wahbah.

Anwar, Syamsul. 2004. Ke Arah Epistemologi Integratif, Mencari Arah Pengembangan Keilmuan dalam Rangka Pemekaran IAIN. Yogyakarta: Pilar Media.

King, Richard. 1999. Orientalism and Religion, Postcolonial theory, India and 'the mystic East'. London: Routledge.

Koentjaraningrat. 2007. Sejarah Teori Antropologi I. Jakarta: UI Press.

Maidani, Abdurrahman Hasan. 2000. Ajnihatu al-Makr alTsalâtsah. Damaskus: Darul Oalam.

Martin, Richard. 1985. Approaches to Islam in Religious Studies. Arizona: University of Arizona Press.

Rahman, Fazlur Rahman, Islam and Modernity: Transformation of an Intellectual Tradition. Chicago dan London: The University of Chicago Press, 1982. 1985. Approaches to Islam in Religious Studies, Arizona: University of Arizona Press.

Samaloyevic, Ahmad. 1998. Falsafatu al-Istisyrâq wa Âstaruhâ fi al-Adab al-'Arabiy al-Mu'âshir. Kairo: Darul Fikri al-Arabi.

Soteriono dan Rita Hanafie. 2007. Filsafat Ilmu dan Metodologi Penelitian. Yogyakarta: Penerbit Andi.

Tholchatul Choir, Ahmad Fanani (Ed.). 2009. Islam dalam Berbagai Pembacaan Kontemporer. Yogyakarta: Pustaka Pelajar. 